\section{Assessment of sampling methods about level of mercury in fish}

\section{Cesare Ciccarelli, ${ }^{1}$ Melina Leinoudi, \\ Angela Marisa Semeraro, ${ }^{1}$ \\ Vittoria Di Trani, ${ }^{1}$ Giuseppe Angelozzi, ${ }^{1}$ \\ Elena Ciccarelli, ${ }^{3}$ Ivan Corti ${ }^{4}$}

${ }^{1}$ Regional Public Health Service

Corporation of Marche - Extended Area

$N^{\circ}$ 5, San Benedetto del Tronto, Italy;

${ }^{2}$ Private Chemist, Reading, UK; ${ }^{3}$ Private

Biologist, Valencia, Spain; ${ }^{4}$ Private

Veterinarian, Milan, Italy

\begin{abstract}
Mercury $(\mathrm{Hg})$ seriously affects some sensitive subgroups of population and the detection of $\mathrm{Hg}$ content in fish and fishery products is one of the most important activities aimed at controlling their safety. In fact, Regulation (EC) No 1881/2006 set maximum levels for certain contaminants in foodstuffs and Regulation (EC) No 333/2007 laid down the methods of sampling and analysis for their control in foodstuffs. As $\mathrm{Hg}$ content highly varies among different fish species depending on a variety of factors and even among members of the same population, sampling methods play a crucial role in the accuracy, precision and statistical significance of $\mathrm{Hg}$ determination. By the use of an analysis method independent probabilistic model, based on the axioms of Kolmogorov's probability theory, this paper aims to assess the relationship between sampling methods set by Regulation (EC) No $333 / 2007$ and the probability to detect compliant or non-compliant outcomes of $\mathrm{Hg}$ in fish.
\end{abstract}

\section{Introduction}

Mercury $(\mathrm{Hg})$ is a metal present in the environment from both natural and anthropogenic sources. Once released into aquatic environment, $\mathrm{Hg}$ undergoes a series of complex transformations and methyl mercury (Me-Hg) is, by far, the most common form of organic $\mathrm{Hg}$ in the food chain. Fish and fishery products are the dominating contributors to $\mathrm{Me}-\mathrm{Hg}$ dietary exposure for humans and could represent a potential harmful element causing even severe health disorders in some population groups such as children and pregnant women (Sheehan et al., 2014; Galimberti et al., 2016; Lavoie et al., 2018). For these reasons analysis of $\mathrm{Hg}$ content in fish is one of the most important activities to take into consideration for the fishery products safety control and the European Union (EU) issued the Regulation (EC) No 1881/2006 setting limits for contaminants in foodstuffs: the $\mathrm{Hg}$ general limit of $0.5 \mathrm{mg} / \mathrm{kg}$ in the edible part and the limit of $1 \mathrm{mg} / \mathrm{kg}$ for some predatory species (European Commission, 2003). The $\mathrm{Hg}$ content varies widely among different fish species depending on size, age, feeding habits, trophic level, marine growing areas and it's higher in predatory fish (Watanabe et al., 2012; Karimi et al., 2013). The processes of bioconcentration and bioamplification along the food chain can determine significant differences of $\mathrm{Hg}$ content, even among organisms from the same group (Bradley et al., 2017).

Considering this, both methods of sampling and analytical methods play a crucial role in the accuracy, precision and statistical significance of $\mathrm{Hg}$ determination in fish and fishery products (EFSA, 2012) and, with this purpose, the EU issued the Regulation (EC) No 333/2007 describing sampling methods for the official control of $\mathrm{Hg}$ levels in foodstuffs (European Commission, 2007).

Data obtained from analysis of those samples are employed in the $\mathrm{Hg}$ risk analysis and in the assessment of human health exposure risk (Moreno-Ortega et al., 2017; Lavoie et al., 2018).

Targeting the crucial role of sampling methods, a probabilistic model, independent from analytical method and based on the axioms of Kolmogorov's probability theory, was developed with the aim of assessing the relationship between sampling methods set by Regulation (EC) No 333/2007 and the probability to detect compliant or noncompliant outcomes for $\mathrm{Hg}$ in fish.

\section{Materials and Methods}

Regulation (EC) No 333/2007 at Annex part B laid down provisions about the concerning sampling plan and defined the incremental sample (IS) as a quantity of material taken from a single place in the lot or sublot and the aggregated sample (AS) as the combined total of all ISs, considered representative of the lot from which it is taken. The complete AS shall be used for the preparation of the laboratory sample (LS), namely a sample intended for the laboratory.

The ISs shall be of similar weight/volume (at least 100g) and their minimum number depends on the lot weight/volume (in $\mathrm{kg}$ or litre): $\mathrm{n} .3$ ISs for lots $<50$; n. 5 ISs for lots $\geq 50$ and $\leq 500$; $n$.
Correspondence: Cesare Ciccarelli, Servizio Veterinario di Igiene degli Alimenti di Origine Animale, ASUR Marche, Area Vasta n. 5, 63074 San Benedetto del Tronto, Italia. Tel.: +39.0735.7937474 - Fax: +39.0735.793529.

E-mail: cesare.ciccarelli@sanita.marche.it

Key words: Mercury, Fish, Sampling method, Statistical assessment, Probabilistic model.

Contributions: the authors contributed equally.

Conflict of interest: the authors declare no potential conflict of interest.

Funding: none.

Received for publication: 5 June 2018.

Revision received: 30 April 2019

Accepted for publication: 24 May 2019

This work is licensed under a Creative Commons Attribution-NonCommercial 4.0 International License (CC BY-NC 4.0).

(C) Copyright: the Author(s), 2019

Licensee PAGEPress, Italy

Italian Journal of Food Safety 2019; 8:7593

doi:10.4081/ijfs.2019.7593

10 ISs for lots $>500$. Large lots, $>15$ tonnes, shall be divided in sublots of 15-30 tonnes. For large fishes, weighting more than about $1 \mathrm{~kg}$, and lots of more than $500 \mathrm{~kg}$ each IS shall consist of the middle part of the fish.

Targeting these statements, three different $\mathrm{Hg}$ mean contents of compliant ISs (specified with letters $l, m$ and $h$ ) and three for non-compliant ISs (specified with letters $L, M$ and $H$ ) are assumed in order to consider a large range of $\mathrm{Hg}$ contamination levels; furthermore we assumed two different contamination's scenarios, the best scenario with low values of $L, M$ and $H$ and, in parallel, the worst scenario with higher values: all the levels are resumed in Table 1. On that basis we determined the minimum number of ISs required to detect noncompliant outcomes for each contamination level and for both different limits.

Assuming that each potential IS has the same probability to be collected and that the collection of one IS does not change the probability of residual ISs to be collected, as stated in the Regulation (EC) No 333/2007, we calculated the probability to obtain an AS with the number of ISs necessary to have non-compliant outcomes. We used the following formula based on the axioms of Kolmogorov's probability theory:

$\operatorname{Pr}(x \mid H, k, n)=P_{i}^{x} \times \prod^{i} \theta H 1 \quad \theta H 2 \ldots \theta H x \quad \theta L 1 \quad \theta L 2 \ldots \theta L(k-x)$

where $\mathrm{x}$ is the number of ISs $>$ legal limit we 
have to consider, $\mathrm{k}$ is the number of ISs to collect to reach a regular $\mathrm{AS}, \mathrm{n}=$ is the number of potential IS to be sampled within the lot, $\theta$ is the ratio between favourable occurrences and all possible occurrences with $\theta \mathrm{H} 1=\mathrm{nH} / \mathrm{n}, \theta \mathrm{H} 2=(\mathrm{nH}-1) /(\mathrm{n}-1), \theta \mathrm{Hx}$ $=(\mathrm{nH}-\mathrm{x}+1) /(\mathrm{n}-\mathrm{x}+1)$ and $\theta \mathrm{L} 1=(\mathrm{nL}-\mathrm{x}) /(\mathrm{n}-\mathrm{x})$, $\theta \mathrm{L} 2=(\mathrm{nL}-\mathrm{x}-1) /(\mathrm{n}-\mathrm{x}-1), \theta \mathrm{L}(\mathrm{k}-\mathrm{x})=(\mathrm{nL}-$ $k+1) /(n-k+1)$ where $H$ is the prevalence of ISs $>$ legal limit and $\mathrm{L}$ is the prevalence of ISs $\leq$ legal limit.

According to Kolmogorov's axioms $\theta \in$ $[0,1], \theta \mathrm{H}+\theta \mathrm{L}=1$ and:

$$
\sum_{i=1}^{k} \operatorname{Pr}(x 1) \operatorname{Pr}(x 2) \ldots \operatorname{Pr}(x k)=1
$$

Moreover, assuming a 0.1 rung from 0.1 to 0.9 for the prevalence of non-compliant ISs, we calculated the $\mathrm{Hg}$ mean content of a lot for all set contamination levels and then - taking the sampling method of concern as a test able to identify lots with the mean content of $\mathrm{Hg}$ exceeding the limit - the number of false positive (FP) and false negative (FN) outcomes were calculated and quantified.

Finally, using a simple probabilistic model, also based on Kolmogorov's axioms, we calculated the probability to detect a noncompliant lot $(x)$ by testing different ASs collected from the same lot with the formula:

$$
\operatorname{Pr}(x \mid C, k)=1-\prod_{i=1}^{k} C 1 C 2 \ldots C k
$$

where $\mathrm{C}$ is the probability to detect a compliant outcome and $\mathrm{k}$ is the number of analysed ASs.

We used the datasheet Libre Office version 5.1.6.2 for the complete computation.

\section{Results}

The most meaningful results of calculations are shown below.

The minimum number of ISs needed to detect non-compliant outcomes for each contamination set level and for both different limits are summarized on Table 2. Only few differences between the limits of $1 \mathrm{mg} / \mathrm{kg}$ and $0.5 \mathrm{mg} / \mathrm{kg}$ were highlighted with an asterisk $(*)$ and therefore these conditions allowed to take into account only the 1 $\mathrm{mg} / \mathrm{kg}$ limit in the following analysis.

Figure 1 shows that the probability to detect non-compliant outcomes in relation to variation in the contamination level and changes in the lot size (expressed as number of potential IS from 102 to 103 until 106) does not change. The figure is related to the limit of $1 \mathrm{mg} / \mathrm{kg}$, best scenarios, but the trend is similar when limit or scenario change.

Figure 2 shows how the probability trend changes relative to different contamination levels and to different number of collected ISs: limit of $1 \mathrm{mg} / \mathrm{kg}$, population size of 106 of potential ISs and best scenario of contamination are the condition of computation.

The trend of probability, increasing the prevalence for all contamination levels (lot

Table 1. Best (bs) and worst (ws) scenarios contamination levels of compliant (c) ISs and non-compliant (nc) ISs for both Hg limits

\begin{tabular}{|c|c|c|c|c|c|c|c|c|}
\hline \multirow[t]{3}{*}{ Contamination level } & \multicolumn{4}{|c|}{$1 \mathrm{mg} / \mathrm{kg}$ limit } & \multicolumn{4}{|c|}{$0,5 \mathrm{mg} / \mathrm{kg}$ limit } \\
\hline & \multicolumn{2}{|c|}{ best scenario } & \multicolumn{2}{|c|}{ worst scenario } & \multicolumn{2}{|c|}{ best scenario } & \multicolumn{2}{|c|}{ worst scenario } \\
\hline & c & ne & c & nc & c & nc & c & nc \\
\hline lL & 0,1 & 1,1 & 0,1 & 1,5 & 0,1 & 0,6 & 0,1 & 0,75 \\
\hline $\mathrm{lM}$ & 0,1 & 1,5 & 0,1 & 1,9 & 0,1 & 0,75 & 0,1 & 1 \\
\hline $\mathrm{lH}$ & 0,1 & 1,9 & 0,1 & 2,4 & 0,1 & 0,9 & 0,1 & 1,5 \\
\hline $\mathrm{mL}$ & 0,5 & 1,1 & 0,5 & 1,5 & 0,25 & 0,6 & 0,25 & 0,75 \\
\hline $\mathrm{mM}$ & 0,5 & 1,5 & 0,5 & 1,9 & 0,25 & 0,75 & 0,25 & 1 \\
\hline $\mathrm{mH}$ & 0,5 & 1,9 & 0,5 & 2,4 & 0,25 & 0,9 & 0,25 & 1,5 \\
\hline hL & 0,9 & 1,1 & 0,9 & 1,5 & 0,4 & 0,6 & 0,4 & 0,75 \\
\hline $\mathrm{hM}$ & 0,9 & 1,5 & 0,9 & 1,9 & 0,4 & 0,75 & 0,4 & 1 \\
\hline$\underline{\mathrm{hH}}$ & 0,9 & 1,9 & 0,9 & 2,4 & 0,4 & 0,9 & 0,4 & 1,5 \\
\hline
\end{tabular}
(mean expressed as $\mathrm{mg} / \mathrm{kg}$ ).

Table 2. Minimum number of ISs necessary to obtain non-compliant outcomes for both different limits and assuming best (bs) and

\begin{tabular}{|c|c|c|c|c|c|c|c|c|c|c|c|c|}
\hline \multirow[t]{3}{*}{ Contamination level } & \multicolumn{6}{|c|}{1 mg/kg } & \multicolumn{6}{|c|}{$0,5 \mathrm{mg} / \mathrm{kg}$} \\
\hline & \multicolumn{2}{|c|}{10} & \multicolumn{2}{|c|}{5} & \multicolumn{2}{|c|}{3} & \multicolumn{2}{|c|}{10} & & \multicolumn{2}{|c|}{3} \\
\hline & bs & ws & bs & ws & bs & ws & bs & ws & bs & ws & bs & ws \\
\hline IL & 10 & 7 & 5 & 4 & 3 & 3 & 10 & 7 & 5 & 4 & 3 & 3 \\
\hline $\mathrm{IM}$ & 7 & 6 & 4 & 3 & 3 & 2 & 7 & 6 & 4 & 3 & 3 & 2 \\
\hline $\mathrm{IH}$ & 6 & 4 & 3 & 2 & 2 & 2 & 6 & 4 & 3 & 2 & 2 & 2 \\
\hline $\mathrm{mL}$ & 9 & 5 & $5^{*}$ & 3 & 3 & 2 & 9 & 5 & $4^{*}$ & 3 & 3 & 2 \\
\hline $\mathrm{mM}$ & 6 & 4 & 3 & 2 & 2 & 2 & 6 & 4 & 3 & 2 & 2 & 2 \\
\hline $\mathrm{mH}$ & 4 & 3 & 2 & 2 & 2 & 1 & 4 & 3 & 2 & 2 & 2 & 1 \\
\hline $\mathrm{hL}$ & 6 & 2 & 3 & 1 & 3 & 1 & 6 & 2 & 3 & 3 & 3 & 1 \\
\hline $\mathrm{hM}$ & 2 & 2 & $1^{*}$ & 1 & 1 & 1 & 2 & 2 & $2^{*}$ & 1 & 1 & 1 \\
\hline$\underline{\mathrm{hH}}$ & 2 & 1 & 1 & 1 & 1 & 1 & 2 & 1 & 1 & 1 & 1 & 1 \\
\hline
\end{tabular}
worst (ws) scenarios.

*Different values between limit $1 \mathrm{mg} / \mathrm{kg}$ and $0.5 \mathrm{mg} / \mathrm{kg}$ at the same contamination level. 
size of 106 ISs, limit $1 \mathrm{mg} / \mathrm{kg}$ and best scenario), instead is shown in the Figure 3.

The $\mathrm{Hg}$ mean content, starting from the assumed contamination levels and the prevalence of compliant and non-compliant outcomes is resumed on Table 3 which considers scenarios, all contamination levels, limit of $1 \mathrm{mg} / \mathrm{kg}$ and increasing prevalence from 0.1 to 0.9: compliant lots are highlighted in green and non-compliant lots in red.

Comparing the compliant outcomes with the compliant $\mathrm{Hg}$ mean content for all assumed conditions, we calculated the number of FP and FN outcomes: Figure 4 resumes the related trend.

Finally, Figure 5 shows the probability to detect non-compliant outcomes by testing several ASs picked up from the same lot, according to the probability of detecting a single non-compliant outcome.

\section{Discussion}

Applied to the sampling methods, as stated by Regulation (EC) No 333/2007 about $\mathrm{Hg}$ content on fish, the use of a probabilistic model, analytical methodindependent and based on the principles of Kolmogorov's probability theory, allows for better understanding features of those methods.

In fact, we demonstrated that, changing the size of the lot to be sampled, represented by the number of potential ISs of the lot, no significant differences among outcomes were found, as shown in Figure 1. This finding represents a crucial issue because if the probability of detecting non-compliant

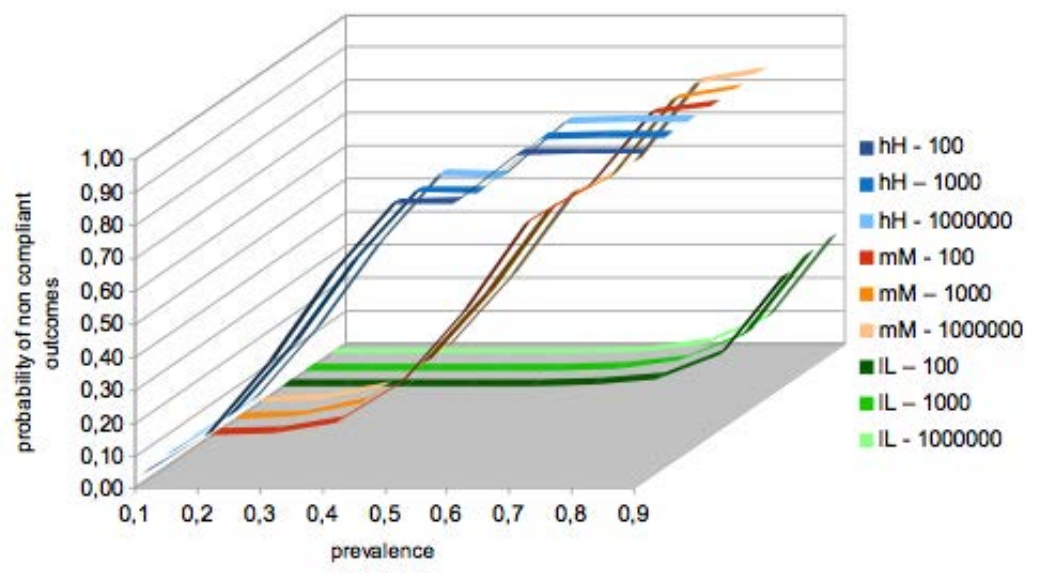

Figure 1. Influence of lot size, considering different prevalence and different contamination levels, on probability to detect non-compliant outcomes (limit $1 \mathrm{mg} / \mathrm{kg}$ and best scenario).

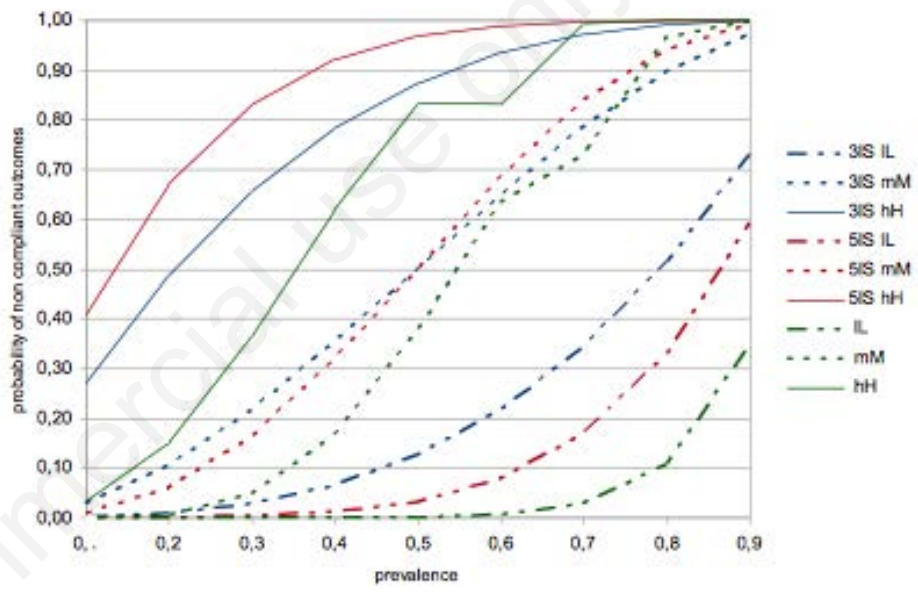

Figure 2. Trend of probability of non-compliant outcomes considering the IS number at different contamination levels (lot size of $10^{6} \mathrm{ISs}$, limit $1 \mathrm{mg} / \mathrm{kg}$ and best scenario).

Table 3. Hg mean content taking into account all contamination levels, limit of $1 \mathrm{mg} / \mathrm{kg}$ and increasing prevalence: cells in italics highlight compliant means and in non-italics the non-compliant ones.

\begin{tabular}{|c|c|c|c|c|c|c|c|c|c|c|}
\hline & & 0,1 & 0,2 & 0,3 & 0,4 & 0,5 & 0,6 & 0,7 & 0,8 & 0,9 \\
\hline \multirow[t]{9}{*}{ Best scenario } & IL & 0,20 & 0,30 & 0,40 & 0,50 & 0,60 & 0,70 & 0,80 & 0,90 & 1,00 \\
\hline & $\mathrm{IM}$ & 0,24 & 0,38 & 0,52 & 0,66 & 0,80 & 0,94 & 1,08 & 1,22 & 1,36 \\
\hline & $\mathrm{IH}$ & 0,28 & 0,46 & 0,64 & 0,82 & 1,00 & 1,18 & 1,36 & 1,54 & 1,72 \\
\hline & $\mathrm{mL}$ & 0,56 & 0,62 & 0,68 & 0,74 & 0,80 & 0,86 & 0,92 & 0,98 & 1,04 \\
\hline & $\mathrm{mM}$ & 0,60 & 0,70 & 0,80 & 0,90 & 1,00 & 1,10 & 1,20 & 1,30 & 1,40 \\
\hline & $\mathrm{mH}$ & 0,64 & 0,78 & 0,92 & 1,06 & 1,20 & 1,34 & 1,48 & 1,62 & 1,76 \\
\hline & $\mathrm{hL}$ & 0,92 & 0,94 & 0,96 & 0,98 & 1,00 & 1,02 & 1,04 & 1,06 & 1,08 \\
\hline & $\mathrm{hM}$ & 0,96 & 1,02 & 1,08 & 1,14 & 1,20 & 1,26 & 1,32 & 1,38 & 1,44 \\
\hline & $\mathrm{hH}$ & 1,00 & 1,10 & 1,20 & 1,30 & 1,40 & 1,50 & 1,60 & 1,70 & 1,80 \\
\hline \multirow[t]{9}{*}{ Worst scenario } & IL & 0,24 & 0,38 & 0,52 & 0,66 & 0,80 & 0,94 & 1,08 & 1,22 & 1,36 \\
\hline & $\mathrm{IM}$ & 0,28 & 0,46 & 0,64 & 0,82 & 1,00 & 1,18 & 1,36 & 1,54 & 1,72 \\
\hline & $\mathrm{IH}$ & 0,33 & 0,56 & 0,79 & 1,02 & 1,25 & 1,48 & 1,71 & 1,94 & 2,17 \\
\hline & $\mathrm{mL}$ & 0,60 & 0,70 & 0,80 & 0,90 & 1,00 & 1,10 & 1,20 & 1,30 & 1,40 \\
\hline & $\mathrm{mM}$ & 0,64 & 0,78 & 0,92 & 1,06 & 1,20 & 1,34 & 1,48 & 1,62 & 1,76 \\
\hline & $\mathrm{mH}$ & 0,69 & 0,88 & 1,07 & 1,26 & 1,45 & 1,64 & 1,83 & 2,02 & 2,21 \\
\hline & $\mathrm{hL}$ & 0,96 & 1,02 & 1,08 & 1,14 & 1,20 & 1,26 & 1,32 & 1,38 & 1,44 \\
\hline & $\mathrm{hM}$ & 1,00 & 1,10 & 1,20 & 1,30 & 1,40 & 1,50 & 1,60 & 1,70 & 1,80 \\
\hline & $\mathrm{hH}$ & 1,05 & 1,20 & 1,35 & 1,50 & 1,65 & 1,80 & 1,95 & 2,10 & 2,25 \\
\hline
\end{tabular}


outcomes is not related to the dimension of the lots to be sampled, that would mean that sampling the whole lot or only one of sublots does not change the probability of obtaining non-compliant outcomes. Therefore, if a large lot were to be splitted and sampled in order to analyse each sublot, as stated by Regulation (EC) No 333/2007, the probability of obtaining non-compliant outcomes would increase, as shown in Figure 5.

An opposite behaviour was observed by changing the number of collected ISs: this number significantly influences the final probability in combination with the contamination level; in the example shown on Figure 2 at low contamination levels noncompliant results have more probability of being detected with 3ISs than with 5ISs or 10ISs and at higher contamination levels the best performances are obtained with 5ISs, whereas with 10ISs the probability is even lower. Unexpectedly, the increase in IS does not correspond with an increase in the probability of detecting non-compliant outcomes.

However, Figure 3 shows, as expected, that the higher the content of $\mathrm{Hg}$ is, the higher the probability of detecting noncompliant outcomes.

Assuming the mean content of $\mathrm{Hg}$ as the target of the sampling method, the model underlines that the number of FP increases for medium contamination levels up to the prevalence of 0.5 , whereas, on the contrary, in case of low contamination levels the number of FP increases only when the prevalence is very high. Conversely, the number of FN shows a different trend, with high values for high contamination levels and decreasing at low level when the prevalence is $>0.5$. That is another crucial issue because it could result in an underestimation of $\mathrm{Hg}$ contamination. especially when the contamination level is high.

\section{Conclusions}

This study developed a probabilistic model that allows a better understanding of the features of sampling methods set by Regulation (EC) No 333/2007 about Hg content in fish and fishery products.

The obtained data demonstrated that: i) the probability to detect non-compliant outcomes does not change with the size of lot to be sampled; ii) this probability is directly conditioned by the $\mathrm{Hg}$ contamination level but not by the number of collected ISs; iii) the number of false negative outcomes could be very high when the contamination level is high and the prevalence is $<0.4$; iv) the increase of the number of analysed samples, collected from the same lot, increases the probability of detecting non-compliant outcomes.
This knowledge could be useful either to improve sampling methods or to better understand the relevance of data analysis reports used during the risk analysis and the assessment of human health exposure risk.

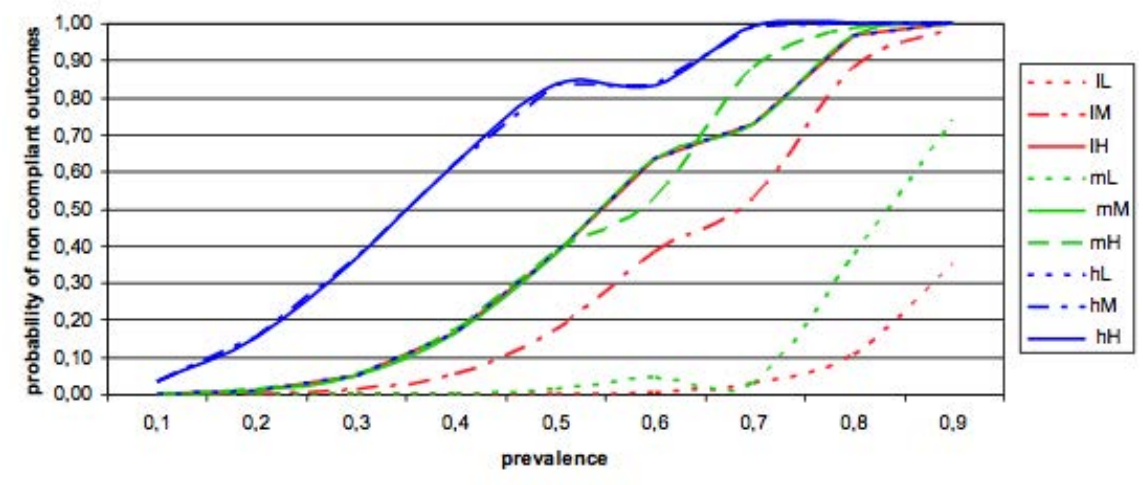

Figure 3. Trend of probability with increasing prevalence for all contamination levels (10 ISs taken, lot size of $10^{6} \mathrm{ISs}$, limit $1 \mathrm{mg} / \mathrm{kg}$ and best scenario).

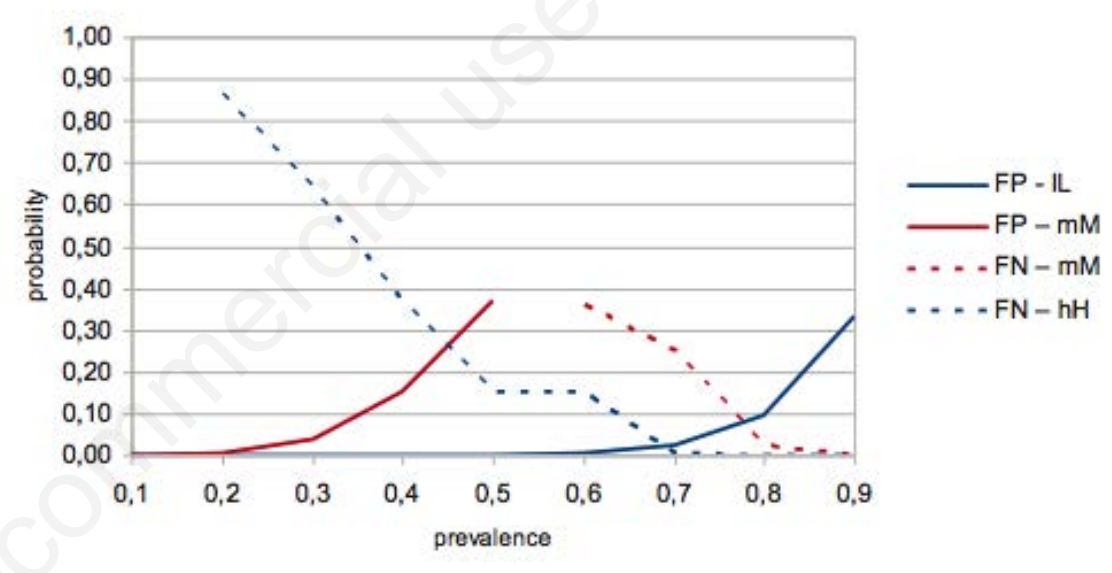

Figure 4. Trend of false positive (FP) and false negative (FN) outcomes with increasing prevalence (all contamination levels, lot size of $10^{6} \mathrm{ISs}$, limit $1 \mathrm{mg} / \mathrm{kg}$ and best scenario). The value of FN for $1 \mathrm{~L}$ contamination level is always 0 .

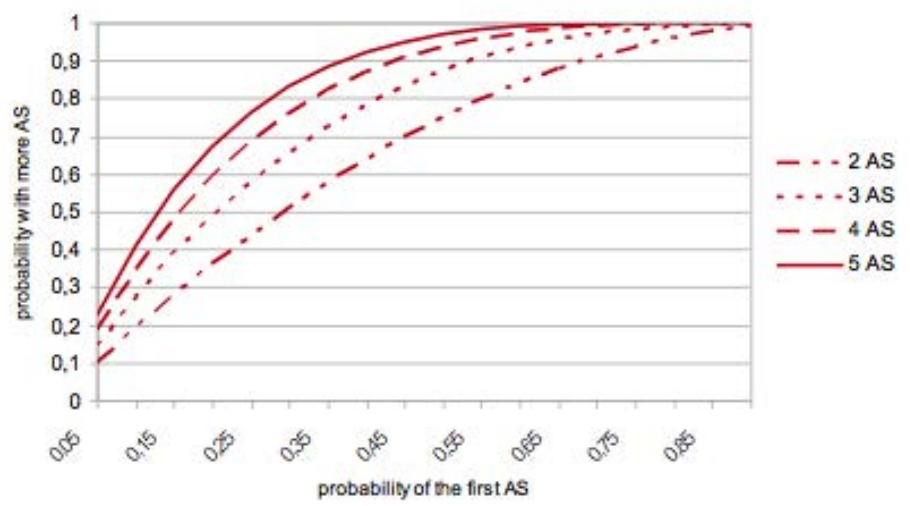

Figure 5. Probability of non-compliant outcomes, by testing different AS collected from the same lot, relative to the probability of a single non-compliant outcome. 


\section{References}

Bradley MA, Barst BD, Basu N, 2017. A review of mercury bioavailability in humans and fish. Int $\mathbf{J}$ Environ Res Public Health 14:1-20.

EFSA, 2012. Scientific Opinion on the risk for public health related to the presence of mercury and methylmercury in food. EFSA J 10:2985.

European Commission, 2006. Regulation of the European Parliament and of the Council of 19 December 2006 setting maximum levels for certain contaminants in foodstuff, 1881/2006/CE. In: Official Journal, L 364/5, 20/12/2006.

European Commission, 2007. Commission Regulation of 28 March 2007 laying down the methods of sampling and analysis for the official control of the levels of lead, cadmium, mercury, inorganic tin, 3-MCPD and benzo(a)pyrene in foodstuff 333/2007/CE. In: Official Journal, L 88/29, 29/03/2007.

Galimberti C, Corti I, Cressoni M, Moretti VM, Menotta S, Galli U, Cambiaghi D, 2016. Evaluation of mercury, cadmium and lead levels in fish and fishery products imported by air in North Italy from extra-European Union countries. Food Control 60:3296-337.

Karimi R, Frisk M, Fisher NS, 2013. Contrasting food web factor and body size relationship with $\mathrm{Hg}$ and $\mathrm{Se}$ concentration in marine biota. PlosOne 8:e74695.

Lavoie AR, Bouffard A, Maranger R, Amyot M, 2018. Mercury transport and human exposure from global marine fisheries.
Sci Rep 18;8:6705.

Moreno-Ortega A, Moreno-Rojas R, Martinez-Alvares JR, Gonzales-Estecha

M, Castro-Gonzales NP, Amaro-Lopez MA, 2017. Probabilistic risk analysis of mercury intake via food consumption in Spain. J Trace Elem Med Biol 43:13541.

Sheehan MC, Burke TA, Acien-Navas A, Breysse PN, McGready J, Fox AM, 2014. Global methylmercury exposure from seafood and risk of developmental neurotoxicity: a systematic review. Bull World Health Organ 92:254-269F.

Watanabe N, Misato T, Inouye M, Yasutake A, 2012. Distribution and chemical form of mercury in commercial fish tissue. $\mathbf{J}$ Toxicol Sci 37:853-61. 